\title{
The combined use of EphA2/MMP-2 expression and MRI findings contributes to the determination of cerebral glioma grade
}

\author{
FANGFANG SUO ${ }^{1}$, BINFENG ZHONG ${ }^{2}$, FANGFANG LU $^{1}$ and ZHIHUI DONG ${ }^{1}$ \\ Departments of ${ }^{1}$ Radiology and ${ }^{2}$ Neurosurgery, Luoyang Central Hospital, Luoyang, Henan 471000, P.R. China
}

Received February 18, 2019; Accepted June 14, 2019

DOI: $10.3892 / 01.2019 .10912$

\begin{abstract}
Glioma is the most aggressive brain tumor and is associated with a high mortality rate. The aim of the present study was to explore the association between matrix metalloproteinase 2 (MMP-2) and ephrin type-A receptor 2 (EphA2) expression in glioma cells, and to investigate the contribution of magnetic resonance imaging (MRI) in glioma classification. A total of 43 patients with pathologically confirmed glioma were divided into two groups as follows: Low-grade (grades I and II; $\mathrm{n}=21$ ) and high-grade (grades IV and IV; $\mathrm{n}=22$ ). Subsequently, immunohistochemistry staining was performed to detect the expression levels of MMP-2 and EphA2 in the low- and high-grade groups. MRI routine and enhanced scans were used to measure the peritumoral edema index (EI), tumor enhancement percentage (EP) and maximum tumor diameter. The results demonstrated that the proportion of MMP-2-positive patients in the high-grade group was $86.36 \%$ (19/22), which was significantly higher than that of the low-grade group $(57.14 \% ; 12 / 21)(\mathrm{P}<0.05)$. Furthermore, the proportion of EphA2-positive patients in the high-grade group was $90.91 \%(20 / 22)$, significantly higher than that in the low-grade group $(4.76 \%$; 1/21) $(\mathrm{P}<0.01)$. In addition, the MRI results indicated that the EI, EP and maximum tumor diameter were significantly higher in the high-grade group compared with the low-grade group $(\mathrm{P}<0.01, \mathrm{P}<0.01$ and $\mathrm{P}<0.05$, respectively). Finally, the expression levels of MMP-2 and EphA2 were significantly associated with the EI, EP and maximum tumor diameter (all $\mathrm{P}<0.05$ ). In conclusion, the expression levels of MMP-2 and EphA2 were positively correlated with
\end{abstract}

Correspondence to: Professor Zhihui Dong, Department of Radiology, Luoyang Central Hospital, 288 Zhongzhou Road, Luoyang, Henan 471000, P.R. China

E-mail: dongzh111@163.com

Abbreviations: MMP-2, matrix metalloproteinase 2; MRI, magnetic resonance imaging; EI, edema index; EP, enhancement percentage; CNS, central nervous system; RTK, receptor tyrosine kinase

Key words: glioma, matrix metalloproteinase 2, ephrin type-A receptor 2 , magnetic resonance imaging glioma invasion. The correlation between these expression levels and MRI assessment of the EI, EP and maximum tumor diameter indicated that the combination of these two methods may be used for the evaluation of the tumor grade and for further clinical treatment applications.

\section{Introduction}

Glioma is the most common primary tumor of the central nervous system (CNS) (1). It was reported in 2014 that glioma accounts for $\sim 30 \%$ of all CNS tumors and $\sim 80 \%$ of all malignant cerebral tumors (2). A study from the Central Brain Tumor Registry of the United States also reported that the 5-year survival rate of patients with glioma in the United States between 2006 and 2010 was $33.8 \%$ (3). According to the 2016 World Health Organization (WHO) classification of CNS tumors, glial tumors are divided into four distinct grades (I-IV) based on the histopathological and molecular features. Grades I and II are classified as low, whereas grades III and IV represent the high grades (4), which are associated with a more aggressive tumor and poorer prognosis.

It has been demonstrated that glioma cell invasiveness and tumor malignancy are positively correlated $(2,5)$. In addition, a number of genes, such as matrix metalloproteinases (MMPs) are involved in the regulation of tumor cell proliferation, migration, invasion, metastasis, peritumoral angiogenesis and regulation of intercellular adhesion, which are crucial for the malignancy of tumors (6,7). MMPs are zinc-dependent proteases that promote extracellular matrix remodeling and degradation, and serve key roles in the signal transduction required for cancer metastasis $(8,9)$. These proteins are released from tumor cells and surrounding matrix, and lead to the degradation of extracellular matrix and basement membrane, which therefore promotes tumor cell invasion (10). In addition, it has been reported that MMP-2 is overexpressed in glioma cells and is associated with tumor invasion and angiogenesis (11-13).

Ephrin (Eph) kinases comprise the largest subfamily of the receptor tyrosine kinase (RTK) superfamily and serve a key role in regulating crucial cellular signaling pathways, including those in cell proliferation, migration and differentiation (14-16). Eph type-A receptor 2 (EphA2) kinase is one of the most common Eph kinases and is associated with the development of various types of cancer (17-19). Non-phosphorylated EphA2 is overexpressed in certain human epithelial malignancies, 
such as prostate epithelial cells, where it is directly associated with tumor cell invasiveness $(20,21)$. Furthermore, it was reported that the PI3K/Akt signaling pathway is associated with malignant glioma progression, whereas PI3K/Akt activation leads to EphA2 phosphorylation, which ultimately promotes glioma cell migration and invasion (22). EphA2 is also directly associated with accelerated angiogenesis (23) and neovascularization (24).

Magnetic resonance imaging (MRI) is a valuable imaging technology that presents the advantages of being a non-traumatic multi-plane imaging technique with non-ionizing radiation (25). These characteristics allow this technique to be one of the most powerful tools for the diagnosis of CNS diseases. MRI scanners use strong magnetic fields, magnetic field gradients and radio waves to generate images of various parts of the body (26). MRI offers the unique advantage over computed tomography (CT) of allowing neurological lesion detection. This tool is characterized by a high degree of soft tissue resolution; it can detect changes in water content of tissue components with high sensitivity and can present vascular structures without using contrast agents (27). At present, enhanced MRI is widely used in the evaluation of glioma (28), assisting in determining glioma grade status (29). The present study aimed to determine the association between MMP-2 and EphA2 expression and MRI parameters and the pathological grade of glioma, in order to facilitate the clinical evaluation, treatment decision-making and prognosis of glioma. The results demonstrated that MMP-2 and EphA2 expression levels were associated with glioma invasiveness. In addition, the correlation between expression levels of these proteins and the MRI parameters edema index (EI), enhancement percentage (EP) and maximum tumor diameter was investigated, indicating that the combined evaluation of MRI and MMP-2 and EphA2 expression levels may be used for tumor malignancy assessment and aid the clinical diagnosis and treatment.

\section{Materials and methods}

Patients. The present study included 43 patients with cerebral glioma (27 men and 16 women, aged 18-65 years, (50.8 \pm 14.2$)$ treated at the Department of Neurosurgery of the Luoyang Central Hospital (Luoyang, China) between November 2016 and December 2017. Patients were divided into low-grade (grades I and II; n=21) and high-grade (grades III and IV; n=22) groups, according to the diagnostic criteria of gliomas from the 2016 WHO classification of CNS tumors (4). Karnofsky performance status (KPS) score was also performed for all patients. KPS score is a performance status scale classifying patients into one out of 10 categories (Table I), ranging between 0: Diseased and 100: Normal, no complaints, no evidence of disease $(30,31)$. The study protocol was approved by the Ethics Committee of the Luoyang Central Hospital and written informed consent was provided by all patients prior to enrollment.

Immunohistochemistry (IHC). Fresh tumor specimens were obtained during tumor resection surgery and fixed with $10 \%$ formalin solution in $4^{\circ} \mathrm{C}$ for $2-3$ weeks. Tumor tissues were embedded in paraffin, cut into $10-\mu \mathrm{m}$ serial sections and placed onto glass slides. Before staining, sections were deparaffinized with xylene, $5 \mathrm{~min}$ for three times. Then, sections were rehydrated in descending alcohol series $(95,90,80$ and 70\%) and antigen retrieval was performed by saline sodium citrate (heated in microwave oven for $30 \mathrm{~min}$ ). One slide was routinely stained with hematoxylin and eosin in $25^{\circ} \mathrm{C}$ for $1-5 \mathrm{~min}$. After blocking in BSA solution $37^{\circ} \mathrm{C}$ for $30 \mathrm{~min}$ (cat. no. P0260; Beyotime Institute of Biotechnology), the other slide was used for IHC staining using mouse anti-human MMP-2 and mouse anti-human EphA2 (Boster cat. no. M00286 and BM0833, both 1:200) monoclonal antibodies detected by streptavidin-peroxidase or 3'-diaminobenzidine visualization kits (OriGene Technologies, Inc.). The distribution, intensity and location of positively stained cells were assessed. Sections incubated with PBS instead of primary antibody were used as negative controls. IHC staining results were examined by light microscopy (magnification x400; Olympus Corporation) and the Image-Pro Plus 6.0 software (Media Cybernetics, Inc.) was used to analyze the percentage of positive cells in each group.

MRI scanning. MRI scans were performed with a Philips Gyroscan Intera 1.5T superconductor MRI scanner (Philips Medical Systems, Inc.). A standard quadrature head coil was used. Spin-echo sequences of MRI scans were included in the axial and sagittal T1-weighted images (T1WIs) and axial T2-weighted images (T2WIs). The contrast agent gadolinium (Gd)-DAPA was administered by fast injection (1-2 min for completion) at the dose of $0.1 \mathrm{mM} / \mathrm{kg}$ in the elbow vein to enhance axial and sagittal T1WI scans. The capture settings were as follows: i) TlWI, repetition time (TR)/time to echo (TE), 431/11 msec; ii) T2WI, TR/TE 4850/120 msec; iii) field-of-view, 24x24 cm; iv) matrix, 256x256; v) number of excitations, 2; vi) band width, $12.5 \mathrm{kHz}$; vii) slice thickness, $5 \mathrm{~mm}$; and viii) interval, $1 \mathrm{~mm}$. The enhanced scan parameters were identical to those of T1WI.

MRI detection for intracranial EI. The edge clarity and uniformity of tumor signals were evaluated by two experienced radiologists. The maximum diameters of the tumor (vertical and coronal or sagittal) were measured on the T1WI enhanced image. The volume of the tumor was estimated by multiplying the vertical diameter with the coronal and sagittal diameters. The same method was used to measure the total volume occupied by the tumor on T2WI images. The volume of the edema was estimated by removing the tumor volume from the total volume, whereas EI was estimated as follows: $\mathrm{EI}=$ edema volume/tumor volume.

MRI detection of intracranial lesion EP. The largest tumor area was selected from T1WIs and the tumor signal intensity was determined by separate non-enhanced and enhanced scans. The EP was estimated as follows: $\mathrm{EP}=[$ (difference between non-enhanced and enhanced scan signal intensity)/(non-enhanced scan signal intensity) x100\%].

Quantitative image analysis. For statistical analysis of IHC staining, positively stained cells were counted in each sample in five randomly selected fields (magnification, $\mathrm{x} 20$ ). The Image-Pro Plus software V6.0 was used to quantify the optical density value of immunostaining. 
Table I. Definition of Karnofsky performance status.

\begin{aligned} \hline Karnofsky performance status & \multicolumn{1}{c}{ Definition } \\ \hline 0 & Deceased \\ 10 & Moribund; fatal processes progressing rapidly \\ 20 & Very sick; hospitalization necessary; active support treatment is necessary \\ 30 & Severely disabled; hospitalization is indicated, although death not imminent \\ 40 & Disabled; requires special care and assistance \\ 50 & Require considerable assistance and frequent medical care \\ 60 & Require occasional assistance, but is able to care for most personal needs \\ 70 & Cares for self; unable to carry on normal activity or do active work \\ 80 & Normal activity with effort; some sign or symptoms of disease \\ 90 & Able to carry on normal activity; minor signs or symptoms of disease \\ 100 & Normal; no complaints; no evidence of disease \end{aligned}

Table II. Demographic characteristics of patients with glioma.

Category Low glioma grade High glioma grade

\begin{tabular}{lcc}
\hline Total cases, $\mathrm{n}$ & 21 & 22 \\
Sex, $\mathrm{n}$ & & \\
Male & 14 & 13 \\
Female & 7 & 9 \\
Age, years & $49.3 \pm 13.2$ & $52.1 \pm 13.9$ \\
BMI, kg/m ${ }^{2}$ & $23.7 \pm 3.1$ & $21.8 \pm 3.8$ \\
KPS score & $80.4 \pm 21.6$ & $58.9 \pm 18.8^{\mathrm{a}}$ \\
\hline
\end{tabular}

${ }^{a} \mathrm{P}<0.01$. BMI, body mass index; KPS, Karnofsky performance status (30).

Statistical analysis. Data are expressed as the mean \pm standard deviation. Statistical analyses were carried out using SPSS 19.0 software (IBM Corp.). Comparisons of parameters among different groups were performed using Student's t-test, Pearson's $\chi^{2}$ test or Fisher's exact test. Correlation analysis was performed using the Pearson's correlation method. $\mathrm{P}<0.05$ was considered to indicate a statistically significant difference.

\section{Results}

Demographic characteristics. The demographic characteristics of the patients with glioma are presented in Table II. Patients with low- $(n=21)$ and high-grade glioma $(n=22)$ were included. The mean ages of the low- and high-grade groups were $49.3 \pm 13.2$ and $52.1 \pm 13.9$ years, respectively, and the mean body mass indexes (BMIs) were 23.7 \pm 3.1 and $21.8 \pm 3.8 \mathrm{~kg} / \mathrm{m}^{2}$, respectively. No significant difference was observed between the two groups regarding these parameters (both $\mathrm{P}>0.05$ ). Furthermore, the sex distribution revealed no significance. The functional status of the patient was scored and results indicated a KPS score of $80.4 \pm 21.6$ and $58.9 \pm 18.8$ for the low-grade and high-grade groups, respectively, and the difference was statistically significant $(\mathrm{P}<0.01)$.
Table III. Expression of MMP-2 and EphA2 in cerebral glioma samples, according to the pathological grade of the tumor.

\begin{tabular}{lcccc}
\hline & \multicolumn{2}{c}{ Glioma grade } & & \\
\cline { 2 - 3 } Category & Low $(\mathrm{n}=21)$ & High $(\mathrm{n}=22)$ & $\chi^{2}$ & P-value \\
\hline MMP-2 & & & 4.38 & $<0.05$ \\
Positive & 12 & 19 & & \\
Negative & 9 & 3 & & \\
EphA2 & & & 28.56 & $<0.01$ \\
Positive & 1 & 20 & & \\
Negative & 20 & 2 & & \\
\hline
\end{tabular}

EphA2, ephrin type-A receptor 2; MMP-2, metalloproteinase.

Expression levels of MMP-2 and EphA2 in glioma tissue sections. IHC staining was used to detect the expression levels of MMP-2 and EphA2 in the low- and high-grade glioma tissue sections. The results are listed in Table III. Positive staining for MMP-2 was observed in the cytoplasm of glioma, vascular endothelial and basal membrane cells. Furthermore, the percentage of MMP-2-positive patients in the high-grade group reached $86.36 \%(19 / 22)$, which was higher than in the low-grade group $(57.14 \%, 12 / 21)$. This difference was statistically significant $(\mathrm{P}<0.05)$. In addition, the proportion of MMP-2-positive cells in the high-grade specimens was significantly higher than in the low-grade tissues (Fig. 1A; $18.52 \pm 7.88$ vs. $45.05 \pm 17.29 \%$; $\mathrm{P}<0.001)$.

The expression levels of EphA2 were examined in glioma cells and in the necrotic and perivascular areas. The percentage of EphA2-positive patients in the high-grade group was $90.91 \%$ (20/22), which was significantly higher than in the low-grade group $(4.76 \%, 1 / 21 ; \mathrm{P}<0.01)$. In addition, the proportion of EphA2-positive cells in the high-grade group was significantly higher than in the low-grade group (Fig. 1B; $19.57 \pm 10.70$ vs. $44.09 \pm 18.50 \%$; $\mathrm{P}<0.001)$.

MRI results of different grades of glioma. The MRI scans of low-grade gliomas indicated that the majority of the 
A

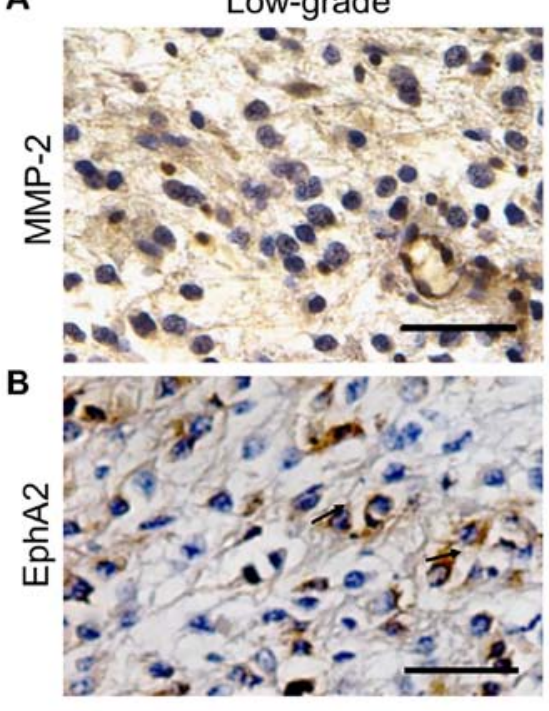

High-grade

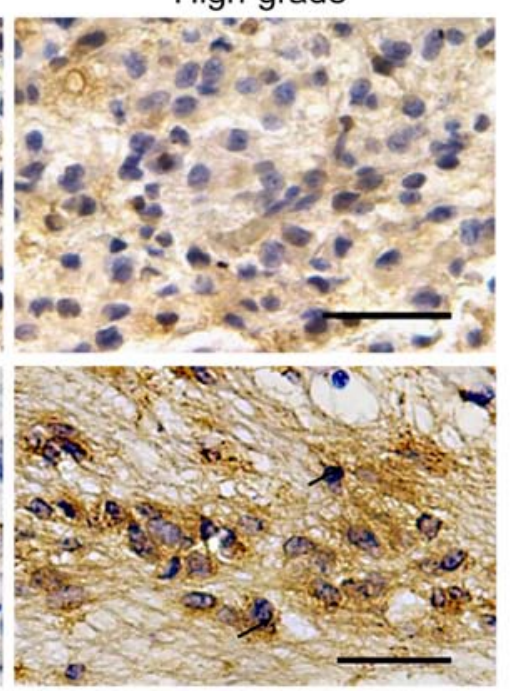

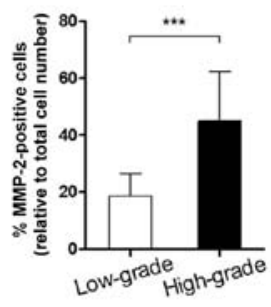

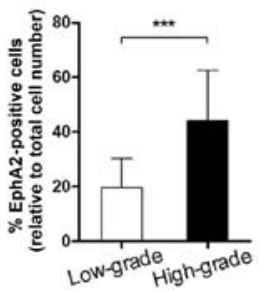

Figure 1. Immunohistochemical staining of glioma tissues. (A) MMP-2 and (B) EphA2 expression was identified by immunofluorescence staining in the cytoplasm of glioma cells. Positive cells were stained brown. Percentages of stained cells are presented in the bar graphs. Data represent the mean \pm standard deviation $(\mathrm{n}=5) .{ }^{* * *} \mathrm{P}<0.001$. Scale bar, $30 \mu \mathrm{m}$. EphA2, ephrin type-A receptor 2; MMP-2, metalloproteinase 2.
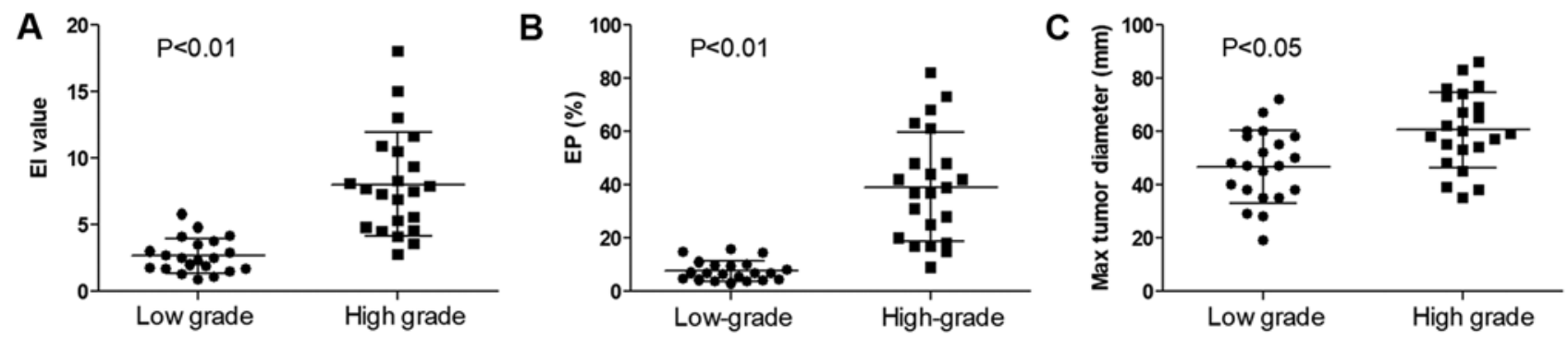

Figure 2. Magnetic resonance imaging parameters measured in patients with glioma. (A) EI value, (B) EP and (C) max tumor diameter (mm) were measured in patients with low- $(n=21)$ and high-grade glioma $(n=22)$. The data are presented as the mean \pm standard deviation. EI, edema index; EP, enhancement percentage; max, maximum.

non-enhanced scan images (T1WIs) presented uniform and/or low signals and that only a limited number of signals were mixed. High or slightly higher signals were displayed in T2WIs and the majority of the signals were uniform and well defined. The enhanced scan revealed no enhancement or slight enhancement, and only one case of bleeding was noted. MRI scans of high-grade gliomas indicated that the majority of the non-enhanced scan images (T1WIs) exhibited low or equal mixed signals, whereas a limited number of signals were low, equal and high mixed. A uniform signal with a high degree of mixing was displayed in T2WIs, with a clear boundary. Enhanced scanning indicated significant uneven enhancement with necrosis and hemorrhage.

The EI around the tumor was significantly higher in the high-grade group than in the low-grade group (Fig. 2A; $7.29 \pm 4.38$ vs. $2.33 \pm 1.53$; $\mathrm{P}<0.01$ ). The EP was also significantly higher in the high-grade group than in the low-grade group (Fig. 2B; $39.27 \pm 19.94$ vs. $6.88 \pm 4.65 \%$; $\mathrm{P}<0.01$ ). The maximum tumor diameter exhibited a similar trend (Fig. 2C; $60.59 \pm 13.99$ vs. $46.71 \pm 13.23 \mathrm{~mm} ; \mathrm{P}<0.05)$.

Correlation between the expression levels of MMP-2 and EphA2 in glioma samples and the MRI results. In order to investigate the association between MMP-2 and EphA2 expression and the MRI parameters, Pearson's correlation analysis was performed. The results indicated that the expression level of MMP-2 was positively correlated with the EI, EP and maximum tumor diameter in the low- and high-grade groups (Fig. 3A, C and E, respectively; all $\mathrm{P}<0.001$ ). Furthermore, the expression level of EphA2 was also positively correlated with all three MRI parameters (Fig. 3B, D and F; all $\mathrm{P}<0.01$ ); in the high-grade group.

\section{Discussion}

A previous study demonstrated that tumor matrix destruction and neovascularization are key factors for tumor cell migration and invasion (32). The MMP-2 protein can degrade the extracellular matrix, causing damage to the tumor vascular endothelial barrier and increasing vascular permeability. This process provides a matrix and space allowing the neovascularization of glioma, which accelerates tumor growth and invasion $(33,34)$. Furthermore, it was reported that $\beta$-catenin downregulation in glioma cells directly reduces the expression levels of epidermal growth factor receptor and MMP-2, which results in a decrease in glioma invasiveness (35). These 
A

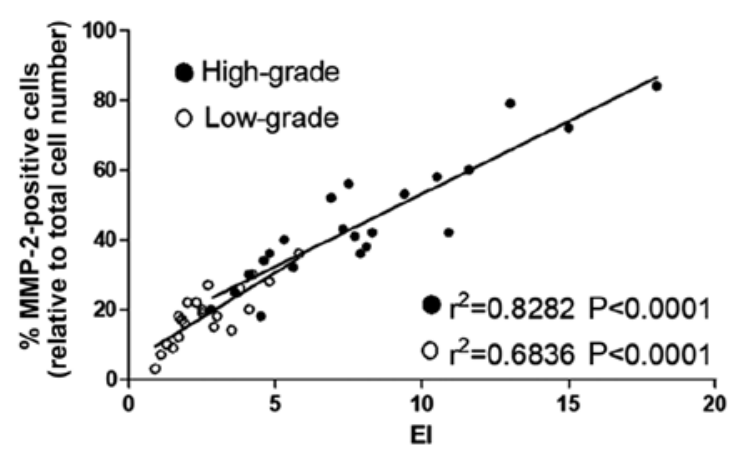

C

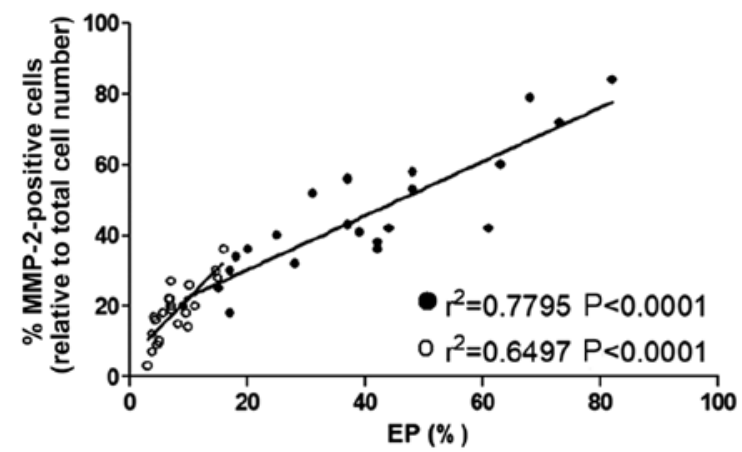

E

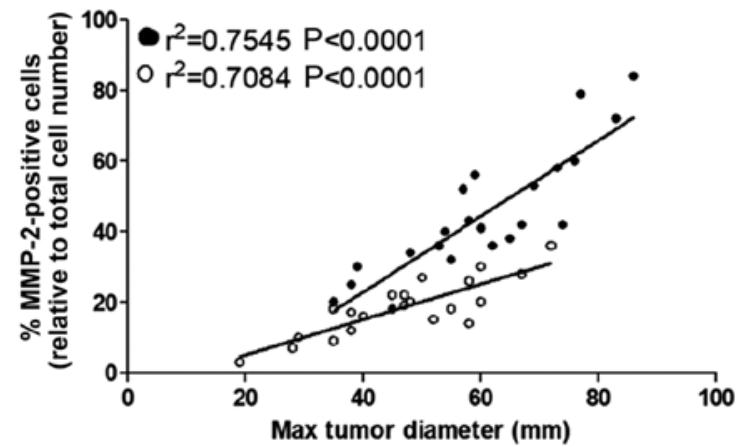

B

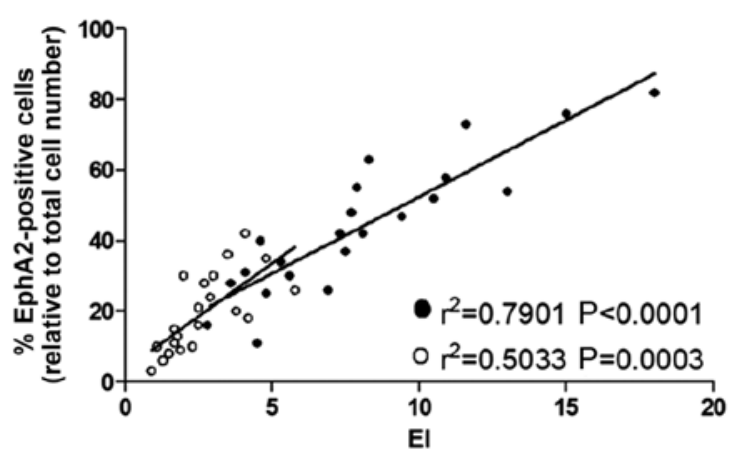

D

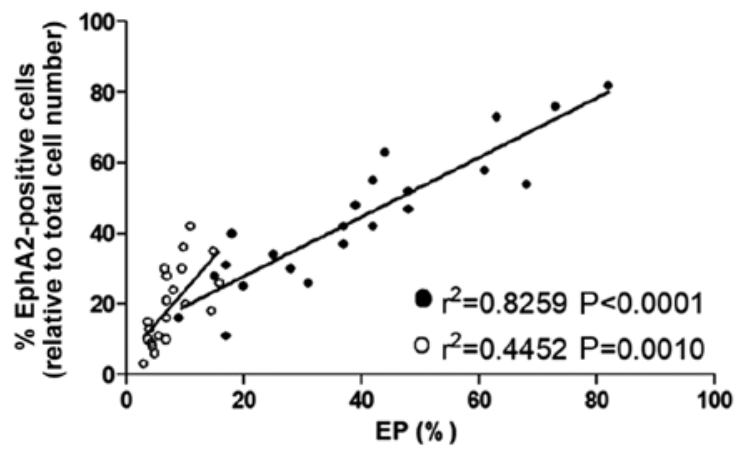

F

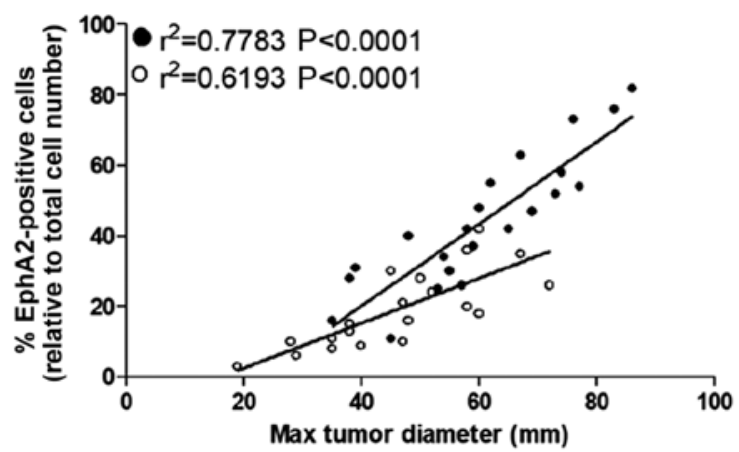

Figure 3. Pearson's correlation analysis of the magnetic resonance imaging parameters and immunohistochemistry results. Scatterplots presenting the correlation between (A) MMP-2 and (B) EphA2 positivity with the EI; (C) MMP-2 and (D) EphA2 positivity with the EP; and (E) MMP-2 and (F) EphA2 positivity with maximum tumor diameter. EI, edema index; EP, enhancement percentage; EphA2, ephrin type-A receptor 2; MMP-2, metalloproteinase 2.

findings suggest that MMP-2 is involved in tumor cell invasion. In addition, it has been demonstrated that MMP-2 expression is associated with the malignant progression of human glioma in vivo (36). RTK signaling pathways serve a crucial role in tumor cell proliferation and migration (14). The Eph kinases represent the largest subfamily of the RTK superfamily (14). Among the distinct subtypes of the Eph kinases, EphA2 kinase is the most common subtype in human cancer types and is overexpressed in various types of human malignancy, including glioblastoma (37). Miao et al (19) reported that Akt could promote EphA2 kinase-induced migration and invasion of glioma cells through phosphorylation of EphA2 serine residues. This protein is therefore considered a key factor in the regulation of malignant tumor progression (20). The present study demonstrated that the number of MMP-2- and EphA2-positive cells in the high-grade glioma tissues was significantly higher than in the low-grade tissues, which was consistent with previous studies $(13,19)$. In addition, the present findings demonstrated that the expression levels of MMP-2 and EphA2 were significantly associated with the progression of glioma, and that they may serve as potential targets for the evaluation of glioma progression.

Glioma is the most common tumor of the CNS. The accurate diagnosis and classification of glioma is crucial for the development of effective treatment methods and outcome improvement. At present, the gold standard for the diagnosis of glioma relies on the pathological examination of tumor tissue excised surgically; however, the disadvantages of this method are that it may induce sampling errors and its invasiveness may cause injury. Preoperative diagnosis and evaluation depend mainly on imaging examination $(29,38)$. Furthermore, novel treatments, including antiangiogenic drugs and image-guided surgery, rely on high-quality imaging during treatment plan evaluation and post-treatment follow-up. CT and MRI are frequently used imaging methods in the clinical setting (39). MRI is characterized by a higher soft tissue resolution compared with $\mathrm{CT}$, and can detect changes in the water content of the 
tissue components with higher sensitivity. MRI is therefore more effective in identifying early lesions (27). In addition, MRI provides abundant imaging information for the identification of certain lesions due to its ability to conduct multiple sequence imaging and to produce multiple image types $(26,27)$. This technique is considered as the gold standard for glioma imaging diagnosis. This method facilitates the precise identification of tumor size and location and the image contrast is improved when paramagnetic contrast agents, including Gd-DAPA for T1WI, are used $(40,41)$. MRI can therefore detect and diagnose malignant tumors more accurately, and allow timely evaluation of the relevant treatment effect. At present, enhanced MRI is widely used in the diagnosis of various types of tumors, including liver cancer, cholangiocarcinoma and glioma (42-44). In addition to conventional and enhanced MRI, specific MRI scanning techniques, namely magnetic resonance perfusion-weighted imaging $(45,46)$ and positron emission tomography/MRI (47) are also used for tumor diagnosis.

It has been demonstrated that tumor necrosis, irregular margins and peritumoral edema are the most significant indicators of tumor grade (48-50). The MRI findings of glioma included typical alterations of MRI characteristics with aggressive tumor progression, and an increase in pathological grade (29). The tumor volume gradually increases and its size became irregular, resulting in an expanding area of peritumoral edema (50). Furthermore, the use of Gd contrast agents significantly enhances tumor detection in the T1WI phase (51), which is associated with neovascularization extent. These indicators may be used to establish the degree of glioma malignancy and provide an important reference for the determination of treatment schedule and glioma prognosis. The results from the present study demonstrated that the EI, EP and maximum tumor diameter were significantly increased in the high-grade glioma group compared with the low-grade glioma group. These data suggest that MRI diagnosis may contribute to the determination of the degree of malignancy in human glioma.

The correlation between MMP-2 and EPhA2 positivity in tumor tissue and MRI parameters was further investigated. The results revealed that the percentage of MMP-2- and EPhA2-positive cells was positively correlated with the EI, EP and maximum tumor diameter. In addition, high-grade glioma exhibited a stronger correlation with MMP-2 and EphA2 positivity compared with low-grade glioma, which suggests that MMP-2 and EphA2 expression levels may gradually increase with the disease progression. These results were consistent with the changes observed following histological examination. The increase in tumor diameter, EI and EP reflected the changes in the tumor anatomy. The expression levels of MMP-2 and EPhA2 may therefore represent a novel approach to evaluate the glioma malignancy grade. The combination of MMP-2 and EPhA2 expression levels and MRI findings may be of clinical value in the diagnosis, grade classification and prognosis of glioma.

In summary, the expression levels of MMP-2 and EphA2 in glioma tissues combined with EI, EP and tumor size assessed following MRI examination may be considered as valuable indicators to evaluate the degree of glioma malignancy. This combined examination method may be more reliable than each technique individually in the early diagnosis and prognosis of glioma, and in the selection of the appropriate therapeutic methods.

\section{Acknowledgements}

Not applicable.

\section{Funding}

No funding was received.

\section{Availability of data and materials}

All data generated or analyzed during this study are included in this published article.

\section{Authors' contributions}

FS performed the experiment, analyzed the data and drafted the manuscript. BZ and FL assisted in the collection of patient's samples and analyzed the data. ZD designed the present study and revised the manuscript. All authors read and approved the final manuscript.

\section{Ethics approval and consent to participate}

The present study was approved by the Ethics Committee of Luoyang Central Hospital (Luoyang, China; approval no. 2016100801), and written informed consent was provided by all patients prior to enrollment.

\section{Patient consent for publication}

Written informed consent was obtained from all patients in advance for the publication of this study.

\section{Competing interests}

The authors declare that they have no competing interest.

\section{References}

1. Appin CL and Brat DJ: Molecular genetics of gliomas. Cancer J 20: 66-72, 2014.

2. Goodenberger ML and Jenkins RB: Genetics of adult glioma. Cancer Genet 205: 613-621, 2012.

3. Ostrom QT, Gittleman H, Farah P, Ondracek A, Chen Y, Wolinsky Y, Stroup NE, Kruchko C and Barnholtz-Sloan JS: CBTRUS statistical report: Primary brain and central nervous system tumors diagnosed in the United States in 2006-2010. Neuro Oncol 15 (Suppl 2): ii1-ii56, 2013.

4. Louis DN, Perry A, Reifenberger G, von Deimling A, Figarella-Branger D, Cavenee WK, Ohgaki H, Wiestler OD, Kleihues P and Ellison DW: The 2016 world health organization classification of tumors of the central nervous system: A summary. Acta Neuropathol 131: 803-820, 2016.

5. Wu W, Lamborn KR, Buckner JC, Novotny PJ, Chang SM, O'Fallon JR, Jaeckle KA and Prados MD: Joint NCCTG and NABTC prognostic factors analysis for high-grade recurrent glioma. Neuro Oncol 12: 164-172, 2010.

6. Bauvois B: New facets of matrix metalloproteinases MMP-2 and MMP-9 as cell surface transducers: Outside-in signaling and relationship to tumor progression. Biochim Biophys Acta 1825: 29-36, 2012. 
7. Yadav L, Puri N, Rastogi V, Satpute P, Ahmad R and Kaur G: Matrix metalloproteinases and cancer-roles in threat and therapy. Asian Pac J Cancer Prev 15: 1085-1091, 2014.

8. Fingleton B: Matrix metalloproteinases: Roles in cancer and metastasis. Front Biosci 11: 479-491, 2006.

9. Martin MD and Matrisian LM: The other side of MMPs: Protective roles in tumor progression. Cancer Metast Rev 26: 717-724, 2007.

10. Egeblad M and Werb Z: New functions for the matrix metalloproteinases in cancer progression. Nat Rev Cancer 2: 161-174, 2002.

11. Cho HJ, Park JH, Nam JH, Chang YC, Park B and Hoe HS Ascochlorin Suppresses MMP-2-Mediated Migration and Invasion by targeting FAK and JAK-STAT signaling cascades. J Cell Biochem 119: 300-313, 2018.

12. Farina P, Tabouret E, Lehmann P, Barrie M, Petrirena G, Campello C, Boucard C, Graillon T, Girard N and Chinot O: Relationship between magnetic resonance imaging characteristics and plasmatic levels of MMP2 and MMP9 in patients with recurrent high-grade gliomas treated by Bevacizumab and Irinotecan. J Neurooncol 132: 433-437, 2017.

13. Ou Y, Wu Q, Wu C, Liu X, Song Y and Zhan Q: Migfilin promotes migration and invasion in glioma by driving EGFR and MMP-2 signalings: A positive feedback loop regulation. J Genet Genomics 44: 557-565, 2017.

14. van der Geer P, Hunter T and Lindberg RA: Receptor protein-tyrosine kinases and their signal transduction pathways. Annu Rev Cell Biol 10: 251-337, 1994.

15. Miao $\mathrm{H}$ and Wang B: Eph/ephrin signaling in epithelial development and homeostasis. Int J Biochem Cell Biol 41: 762-770, 2009.

16. Kullander K and Klein R: Mechanisms and functions of Eph and ephrin signalling. Nat Rev Mol Cell Biol 3: 475-486, 2002.

17. Nakamoto $M$ and Bergemann AD: Diverse roles for the Eph family of receptor tyrosine kinases in carcinogenesis. Microsc Res Tech 59: 58-67, 2002.

18. Pasquale EB: Eph-ephrin bidirectional signaling in physiology and disease. Cell 133: 38-52, 2008.

19. Miao H, Li DQ, Mukherjee A, Guo H, Petty A, Cutter J, Basilion JP, Sedor J, Wu J, Danielpour D, et al: EphA2 mediates ligand-dependent inhibition and ligand-independent promotion of cell migration and invasion via a reciprocal regulatory loop with Akt. Cancer Cell 16: 9-20, 2009.

20. Ireton RC and Chen J: EphA2 receptor tyrosine kinase as a promising target for cancer therapeutics. Curr Cancer Drug Targets 5: 149-157, 2005.

21. Zeng G, Hu Z, Kinch MS, Pan CX, Flockhart DA, Kao C, Gardner TA, Zhang S, Li L, Baldridge LA, et al: High-level expression of EphA2 receptor tyrosine kinase in prostatic intraepithelial neoplasia. Am J Pathol 163: 2271-2276, 2003.

22. Miao H, Gale NW, Guo H, Qian J, Petty A, Kaspar J, Murphy AJ, Valenzuela DM, Yancopoulos G, Hambardzumyan D, et al: EphA2 promotes infiltrative invasion of glioma stem cells in vivo through cross-talk with Akt and regulates stem cell properties. Oncogene 34: 558-567, 2015.

23. Cheng N, Brantley DM, Liu H, Lin Q, Enriquez M, Gale N, Yancopoulos G, Cerretti DP, Daniel TO and Chen J: Blockade of EphA receptor tyrosine kinase activation inhibits vascular endothelial cell growth factor-induced angiogenesis. Mol Cancer Res 1: 2-11, 2002.

24. Ogawa K, Pasqualini R, Lindberg RA, Kain R, Freeman AL and Pasquale EB: The ephrin-A1 ligand and its receptor, EphA2, are expressed during tumor neovascularization. Oncogene 19: 6043-6052, 2000.

25. Khurshid SJ and Hussain AM: Nuclear magnetic resonance imaging (MRI). J Pak Med Assoc 41: 259-264, 1991.

26. Cavezian R, Cabanis EA, Pasquet G, Iba-Zizen MT, Le Bihan D, Tamraz J and Roger B: Magnetic resonance imaging. Physical principles, current biomedical applications, maxillofacial perspectives. Actual Odontostomatol (Paris) 40: 219-232, 1986 (In French).

27. Guy RL, Benn JJ, Ayers AB, Bingham JB, Lowy C, Cox TC and Sonksen PH: A comparison of CT and MRI in the assessment of the pituitary and parasellar region. Clin Radiol 43: 156-161, 1991

28. Qi S, Yu L, Li H, Ou Y, Qiu X, Ding Y, Han H and Zhang X Isocitrate dehydrogenase mutation is associated with tumor location and magnetic resonance imaging characteristics in astrocytic neoplasms. Oncol Lett 7: 1895-1902, 2014.
29. Puttick S, Bell C, Dowson N, Rose S and Fay M: PET, MRI, and simultaneous PET/MRI in the development of diagnostic and therapeutic strategies for glioma. Drug Discov Today 20: 306-317, 2015.

30. Crooks V, Waller S, Smith T and Hahn TJ: The use of the karnofsky performance scale in determining outcomes and risk in geriatric outpatients. J Gerontol 46: M139-M144, 1991.

31. de Haan R, Aaronson N, Limburg M, Hewer RL and Van Crevel H: Measuring quality of life in stroke. Stroke 24: 320-327, 1993.

32. Okada A: Roles of matrix metalloproteinases and tissue inhibitor of metalloproteinase (TIMP) in cancer invasion and metastasis. Gan To Kagaku Ryoho 26: 2247-2252, 1999 (In Japanese).

33. Itoh T, Tanioka M, Yoshida H, Yoshioka T, Nishimoto $\mathrm{H}$ and Itohara S: Reduced angiogenesis and tumor progression in gelatinase A-deficient mice. Cancer Res 58: 1048-1051, 1998.

34. Rao JS: Molecular mechanisms of glioma invasiveness: The role of proteases. Nat Rev Cancer 3: 489-501, 2003

35. Yue X, Lan F, Yang W, Yang Y, Han L, Zhang A, Liu J, Zeng H, Jiang T, Pu P and Kang C: Interruption of $\beta$-catenin suppresses the EGFR pathway by blocking multiple oncogenic targets in human glioma cells. Brain Res 1366: 27-37, 2010.

36. Chicoine MR and Silbergeld DL: The in vitro motility of human gliomas increases with increasing grade of malignancy. Cancer 75: 2904-2909, 1995.

37. Wykosky J, Gibo DM, Stanton C and Debinski W: EphA2 as a novel molecular marker and target in glioblastoma multiforme. Mol Cancer Res 3: 541-551, 2005.

38. Langer A: A systematic review of PET and PET/CT in oncology: A way to personalize cancer treatment in a cost-effective manner? BMC Health Serv Res 10: 283, 2010.

39. Ross R: Advances in the application of imaging methods in applied and clinical physiology. Acta Diabetol 40 (Suppl 1): S45-S50, 2003.

40. Caravan P, Ellison JJ, McMurry TJ and Lauffer RB: Gadolinium(III) chelates as MRI contrast agents: Structure, dynamics, and applications. Chem Rev 99: 2293-2352, 1999.

41. Zhou Z and Lu ZR: Gadolinium-based contrast agents for magnetic resonance cancer imaging. Wiley Interdiscip Rey Nanomed Nanobiotechnol 5: 1-18, 2013.

42. Ye F, Liu J and Ouyang H: Gadolinium ethoxybenzyl diethylenetriamine pentaacetic acid (Gd-EOB-DTPA)-enhanced magnetic resonance imaging and multidetector-row computed tomography for the diagnosis of hepatocellular carcinoma: A systematic review and meta-analysis. Medicine (Baltimore) 94: e1157, 2015

43. Ying SH, Teng XD, Wang ZM, Wang QD, Zhao YL, Chen F and Xiao WB: Gd-EOB-DTPA-enhanced magnetic resonance imaging for bile duct intraductal papillary mucinous neoplasms. World J Gastroenterol 21: 7824-7833, 2015.

44. Chung C, Metser U and Menard C: Advances in magnetic resonance imaging and positron emission tomography imaging for grading and molecular characterization of glioma. Semin Radiat Oncol 25: 164-171, 2015.

45. Zuo N, Cheng J and Jiang T: Diffusion magnetic resonance imaging for Brainnetome: A critical review. Neurosci Bull 28: 375-388, 2012.

46. Jahng GH, Li KL, Ostergaard L and Calamante F: Perfusion magnetic resonance imaging: A comprehensive update on principles and techniques. Korean J Radiol 15: 554-577, 2014.

47. Ledezma CJ, Chen W, Sai V, Freitas B, Cloughesy T, Czernin J and Pope W: 18F-FDOPA PET/MRI fusion in patients with primary/recurrent gliomas: Initial experience. Eur J Radiol 71: 242-248, 2009.

48. Chen W and Silverman DH: Advances in evaluation of primary brain tumors. Semin Nucl Med 38: 240-250, 2008

49. Costello JF: DNA methylation in brain development and gliomagenesis. Front Biosci 8 (Suppl): S175-S184, 2003.

50. Carlson MR, Pope WB, Horvath S, Braunstein JG, Nghiemphu P, Tso CL, Mellinghoff I, Lai A, Liau LM, Mischel PS, et al: Relationship between survival and edema in malignant gliomas: Role of vascular endothelial growth factor and neuronal pentraxin 2. Clin Cancer Res 13: 2592-2598, 2007.

51. Pope WB, Sayre J, Perlina A, Villablanca JP, Mischel PS and Cloughesy TF: MR imaging correlates of survival in patients with high-grade gliomas. AJNR Am J Neuroradiol 26: 2466-2474, 2005 . 